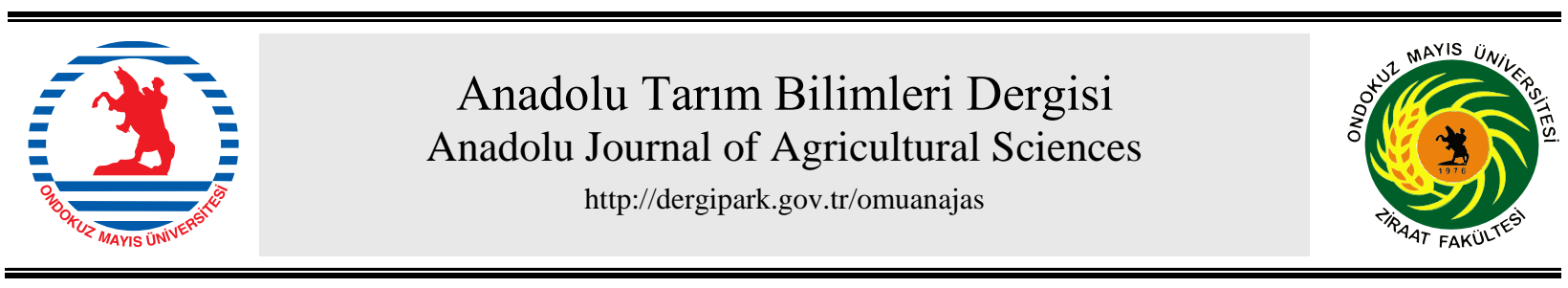

\section{Araştırma/Research}

Anadolu Tarım Bilim. Derg./Anadolu J Agr Sci, 36 (2021)

ISSN: 1308-8750 (Print) 1308-8769 (Online) doi: 10.7161/omuanajas.826960

\title{
Yüksek Çözünürlüklü İnsansız Hava Aracı Görüntülerinde Bitki Gölgelerinin Tespit Edilmesi
}

\author{
๑Emre Tunca ${ }^{\mathrm{a}^{*}}$, ๑Eyüp Selim Köksal ${ }^{\mathrm{a}}$ \\ ${ }^{a}$ Ondokuz Mayıs Üniversitesi, Ziraat Fakültesi, Tarımsal Yapılar ve Sulama Bölümü, Samsun, Türkiye \\ *Sorumlu yazar/corresponding author: emre.tunca@omu.edu.tr
}

Geliş/Received 16/11/2020 Kabul/Accepted 24/05/2021

\begin{abstract}
ÖZET
Yüksek çözünürlüklü multispektral görüntüler tarım alanlarının izlenmesinde oldukça yararlı bilgiler sunmaktadır. Fakat bu görüntülerdeki gölge alanları spektral yansıma oranı ve termal verileri direk olarak etkilemektedir. $\mathrm{Bu}$ nedenle gölge alanlarının tespit edilmesi ve filtrelenmesi, yüksek çözünürlüklü görüntülere dayalı olarak gerçekleştirilen çalışmalardaki başarı oranını arttıracaktır. Görüntülerde bulunan gölge alanları sınıflandırma yöntemleri ile tespit edilmektedir. Fakat, bu yöntemlerin insansız hava aracından (IHHA) elde edilen yüksek çözünürlüklü multispektral görüntülerde kullanımı üzerine gerçekleştirilmiş araştırma sayısı oldukça azdır. Bu çalışmanın amacı üç farklı görüntü sınıflandırma yönteminin (eğitimli sınıflandırma, multispektral görüntü ile sınıflandırma ve sınıf olasılığı) İHA' dan elde edilen multispektral görüntülerdeki gölge alanlarını tespit etmedeki başarısının değerlendirilmesidir. Her bir sınıflandırma yönteminin başarısı, görüntüde manuel yöntem ile belirlenen gölge alanları ile değerlendirilmiştir. Çalışma sonucunda bitki gölgeleri en hassas (\%94) kırmızı kenar multispektral görüntüsü kullanılarak gerçekleştirilen sınıflandırma ile elde edilirken, en düşük hassasiyet (\%74) ise eğitimli sınıflandırma yöntemi ile hesaplanmıştır.
\end{abstract}

\section{Crop Shadow Detection in High Resolution Un-Manned Air Vehicle Images}

\section{ABSTRACT}

High-resolution multispectral image provides useful information for monitoring agricultural areas. However, shadow areas in these images directly affect spectral reflectance and thermal data. For this reason, detecting and removing of shadow areas will increase the success rate of studies that performed based on high resolution images. Shadows can be detected by using image classification methods. However, researches related to use of these methods in high resolution images obtained from unmanned air vehicles are quite limited. Therefore, the aim of this study is evaluation of three different image classification methods (supervised classification, multispectral image classification and class probability) for detecting shadows of bell pepper plant. Each classification method was compared with the shadow areas which manually determined in the image. The results show that, while the most accurately bell pepper shadows detected by using Red Edge multispectral image (94\%), the lowest with supervised classification (74\%).
Anahtar Sözcükler:

Multispektral Görüntü Sınıflandırma Gölge Tespiti
Keywords: Multispectral Image Classification Shadow Detection

(C) OMU ANAJAS 2021 


\section{Giriş}

İnsansız Hava Araçları (İHA) sistemleri günümüzde yüksek çözünürlüklü görüntülere olan talebin artması ile hızla gelişen bir teknoloji haline gelmiştir. Son yıllarda İHA sistemleri ormancılık (Shin ve ark., 2019), madencilik (Werner ve ark., 2019), haritacılık (Marques Junior ve ark., 2020) ve tarım (Novák ve ark., 2018) gibi birçok alanda kullanılmaya başlamıştır. Görüntü işleme, malzeme bilimi, konumlama sistemleri (GPS) ve sensör teknolojisindeki gelişmelerle birlikte İHA platformlarının tarım alanındaki kullanım artışı diğer sektörlerden daha fazla gerçekleşmiştir (Boursianis ve ark., 2020). Gelişen bu teknolojinin tarım sektöründe kullanılması sayesinde özellikle küçük ölçekli tarım alanlarının sık aralıklarla izlenmesi olanaklı hale gelmiştir. Massachusetts Institute of Technology (MIT) Rewiew tarafından 2014 yılında yapılan bir araştırmada tarımsal İHA sistemleri çığır açan teknoloji listesinde ilk sırada yer almaktadır (MIT Technology Review, 2020). Günümüzde İHA sistemleri santimetre düzeyinde sağladığı yüksek yersel çözünürlüklü görüntülerle tarımda sulama yönetimi (Nieto ve ark., 2019; Ortega-Farías ve ark., 2016), bitkilerin gelişme dönemi boyunca izlenmesi (Berni ve ark., 2009), verim tahmini (Tunca ve ark., 2018), hastalık ve zararlıların tespiti (Peña ve ark., 2015), bitki besleme yönetimi (Kaivosoja ve ark., 2013) ve yabancı otların tespiti (Zheng ve ark., 2018) gibi çalışmalarda başarılı bir biçimde kullanılmaktadır. Fakat İHA görüntülerindeki yersel çözünürlüğün artması ile söz konusu verinin transferi, depolanması, görüntü işleme süresinin artması, rüzgâr gibi çevresel etmenler etkisiyle bulanıklık (blur) oluşması ve görüntüdeki objelerin gölgesi gibi yüksek çözünürlüklü görüntülerde oluşabilen bir takım yeni sorunlar ortaya çıkmıştır. İHA görüntülerinde nesnelerin gölgeleri genel olarak göz ardı edilmesine rağmen, bu gölge alanları spektral yansıma ve yüzey sicaklığı verilerini doğrudan etkileyebilmektedir. Bu sebeple görüntüdeki gölge hücrelerinin dikkate alınmaması durumunda bitki stres koşullarının belirlenmesi, bitki su tüketimi haritalanması ve bitki izleme-değerlendirme gibi İHA görüntülerine dayalı gerçekleştirilen çalışmalarda sonuçların hassasiyetinde azalma kaçınılmazdır.

İHA görüntülerindeki gölgeler, bina veya bitki gibi belirli seviyede yüksekliğe sahip objelerin güneş 1şı̆̆ına direk olarak maruz kalmaları sonucu ortaya çıkmaktadır. Yapılan bazı araştırmalarda gölge hakkındaki bilgiler kullanılarak nesnelerin geometrik şekilleri (Lillesand ve Kiefer, 2000), 1şık kaynağının konumu (Bethsda, 1997), ve nesnelerin boyu (Sirmacek ve Unsalan, 2008) başarılı bir biçimde tahmin edilmiştir. Fakat gölge altında bulunan çalışma alanlarına ait değerlendirilmede yanılgılar ortaya çıkabilmektedir. Diğer bir deyişle gölge altındaki alanlarda spektral yansıma oranı ve yüzey sıcaklık değerleri daha düşük belirlenebilmektedir. Sonuç olarak gölge etkisi görüntülerin sınıflandırılmasında birtakım sorunlar meydana getirmekte ve bu durum bitkilerin İHA sistemleri ile izlenmesine dayalı gerçekleştirilen çalışmalarda hatalı sonuçların üretilmesine neden olmaktadır. Bu nedenle görüntülerdeki gölge etkilerinin ortadan kaldırılması için kullanılan yöntemlerin incelenmesi ve değerlendirilmesi gerekmektedir.

Uzaktan algılanmış görüntülerde gölgelerin tespiti için yapılan çalışmalar genel olarak 4 farklı kategoride ele alınmaktadır. Bunlar; i) Eğitimsiz Sınıflandırma (unsupervised classification), ii) Yapay Sinir Ağları ve Makine Öğrenmesi gibi istatistiki yöntemler kullanılarak Eğitimli Sınıflandırma (supervised classification) iii) Vejetasyon indekslerine dayalı yöntemler ve iv) fiziksel yöntemlerdir. Xia ve ark. (2009)' da ton-doygunluk-yoğunluk (HSI) renk uzayında benzeşim yayılım kümelenmesi (affinity propagation clustering) yöntemi kullanılarak gölgelerin belirlenmesi amacıyla eğitimsiz sınıflandırma gerçekleştirilmiş̧ir. Shiting ve Hong (2013) tarafından yapılan bir çalışmada gölge köşelerinin belirlenmesi için k-ortalamalar kümesi (k-means cluster) yöntemi kullanılmıştır. Çalışma sonucunda gölge köşe noktalarının başarılı bir biçimde filtrelendiği belirtilmiştir. Yapılan diğer bir çalışmada uzaktan algılanmış görüntülerden gölgelerin tespit edilebilmesi için RGB yerine renk uzayları kullanılarak nesne tabanlı sınıflandırma başarılı bir biçimde gerçekleştirilmiştir (Kumar ve ark., 2002). Siala ve ark. (2004) destek vektörlerini kullanarak görüntülerdeki gölgeleri tespit etmek için eğitimli sınıflandırma yöntemini kullanmıştır. Zhu ve Woodcock (2012)' de ise Landsat görüntülerindeki bulut gölgelerinin tespiti için nesneye dayalı eğitimli sınıflandırma gerçekleştirmiştir. Rosin ve Ellis (1995)' de uzaktan algılanmış görüntüdeki gölgelerin tespiti için çeşitli vejetasyon indekslerinde farklı eşik değerleri üzerine araştırma gerçekleştirilmiştir. Choi ve Bindschadler (2004) tarafından gerçekleştirilen bir çalışmada Landsat 7 uydu görüntülerinde bulut ve bulut gölgelerinin tespiti için normalize edilmiş kar değişim indeksi (NDSI) kullanılmıştır. Yapılan bir diğer çalışmada ise bitki gölgelerinin ayrıştırılması amacıyla ilk olarak su yüzeyleri ve bitki örtüsünün birbirinden ayrılması için Normalize Edilmiş Su Değişim İndeksi (NDWI) ve Normalize edilmiş vejetatif değişim indeksi (NDVI) kullanılmıştır. Su yüzeylerinin filtrelenmesi sonucunda elde edilen görüntülere en yüksek benzerlik sinıflandırması (MLC) ve destek vektör makinaları (SVM) yöntemleri uygulanarak bitki gölgeleri sınıflandırılmıştır (Qiao ve ark., 2017). Sandnes (2011), güneşin pozisyonu ve gölge uzunluğunu kullanarak, sensörün yaklaşık konumunu tahmin etmiştir. Huang ve Chen (2009) hava platformlarından çekilen videolarda gölgelerin tespit edilebilmesi için yeni bir algoritma geliştirilmiştir. Çalı̧̧ma sonucunda bu algoritmaların meyve ağaçlarına ait gölge tespiti için başarılı bir biçimde kullanılabileceği belirtilmiştir. Yapılan bu çalışmalara ek olarak multispektral görüntülerdeki gölge alanlarının vejetasyon indeksi 
üzerine olan etkilerinin belirlenmesi üzerine birtakım araştırmalar gerçekleştirilmiştir. Hsieh ve ark. (2016)' da gölgelenen alanların spektral karakteristikleri analiz edilmiş ve gölge altında olan ve olmayan alanlardaki NDVI değişimlerinin ortaya konulması amaçlanmıştır. Çalışma sonucunda gölge alanları ve bitki örtüsünün ortalama ndvi değeri sırasıyla 0.38 ve 0.64 olarak tespit edilmiştir. Poblete ve ark. (2018) tarafindan gerçekleştirilen bir çalışmada İHA görüntülerine SHIFT ve K-means++ sinıflandırma yöntemleri kullanılarak bitki örtüsüne ait gölge alanları tespit edilmiş ve filtrelenmiştir. Çalışmadan elde edilen sonuçlara göre gölge alanlarının filtrelenmesi, termal görüntülerden hesaplanan Bitki su stres indeksi (CWSI) ve gövde su potansiyeli arasındaki ilişkiyi güçlendirdiği belirtilmiştir. Aboutalebi ve ark. (2019)' da üzüm bağlarında gölge alanlarının NDVI ve bitki su tüketimi hesaplamalarında istatistiksel olarak önemli düzeyde etki yaptı̆̆ belirtilmiştir.

Literatürde gölge tespiti üzerine belirli sayıda çalışma olmasına rağmen, yüksek çözünürlüklü İHA görüntülerinde bitki gölgelerinin tespiti üzerine yapılmış araştırma oldukça azdır. Ayrıca yapılan çalışmaların büyük çoğunluğu orman ağaçları veya üzüm bağları üzerine gerçekleştirilmiş ve sebze bitkilerinde gölge tespiti üzerine yapılmış herhangi bir çalışma bulunmamaktadır. $\mathrm{Bu}$ nedenle, bu çalışmanın amacı yüksek çözünürlüklü multispektral İHA görüntülerinden dolmalık biber bitkisine ait gölgelerin tespit edilmesinde farklı sınıflandırma yöntemlerinin değerlendirilmesidir. Bu amaçla yüksek çözünürlüklü İHA görüntüsünde eğitimli sınıflandırma, multispektral görüntü ile sınıflandırma ve sınıf olasılığı yöntemleri kullanılarak bitki gölgeleri filtrelenmiş ve elde edilen sonuçlar, yerde belirlenen gölge alanları ile karşılaştırılmıştır.

\section{Materyal ve Yöntem}

\subsection{Materyal}

Çalı̧̧ma 2019 yılında Samsun ili Bafra ilçesinde yer alan Karadeniz Tarımsal Araştırma Enstitüsü Bafra Deneme İstasyonunda ( $\left.41^{\circ} 36^{\prime} 8^{\prime \prime} \mathrm{K}, 35^{\circ} 55^{\prime} 8^{\prime \prime} \mathrm{D}\right)$ gerçekleştirilmiştir (Şekil 1). Araştırma yerine ait topraklar genel olarak kil bünyeli özellik göstermektedir (Köksal ve ark., 2017). Çalışma alanı Thornthwaite iklim sınıflandırmasına göre yarı nemli iklim sınıfında yer almaktadır (MGM, 2020). Uzun yıllar iklim verilerine göre ortalama yıllık toplam yağış miktarı $694 \mathrm{~mm}$, ortalama en yüksek sıcaklık ve en düşük sıcaklıklar sırasıyla Ağustos ve Şubat aylarında $27^{\circ} \mathrm{C}$ ve $3.7^{\circ} \mathrm{C}$ olarak gerçekleşmiştir.

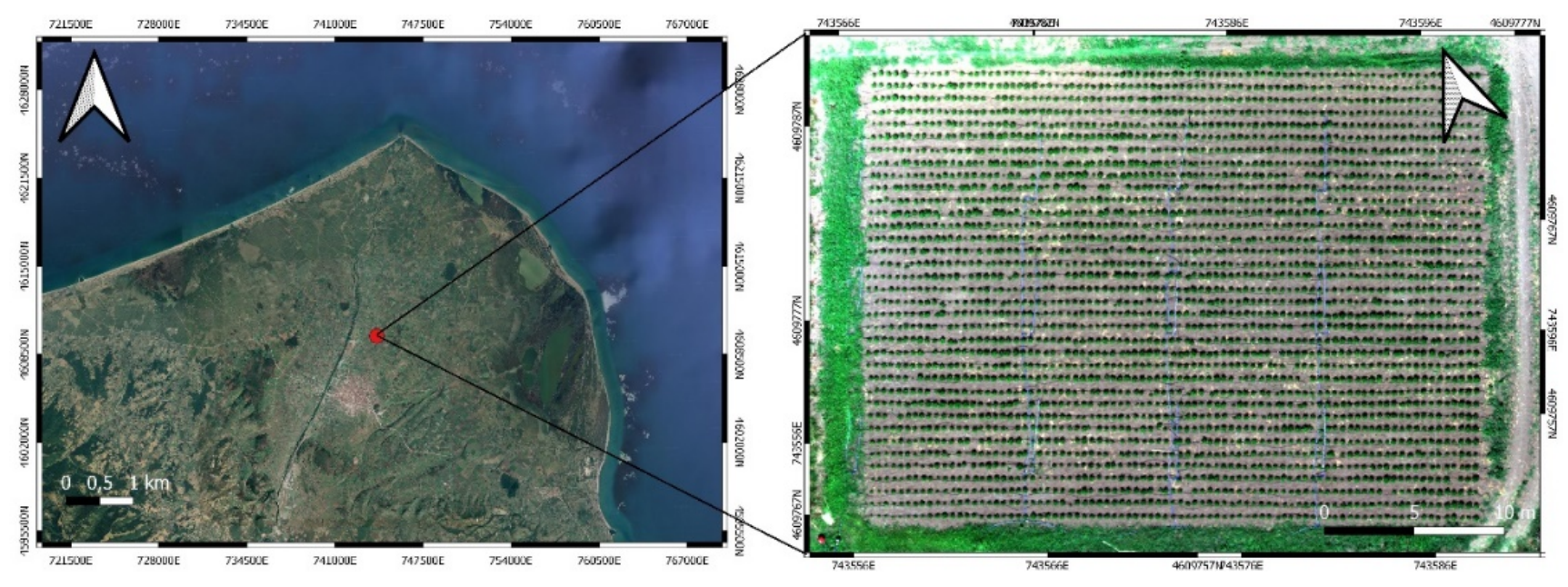

Şekil 1. Çalışma Alanının coğrafi konumu.

Figure 1. Geographical location of the study area.

Araştırmada bitkilerin sulanmasında damla sulama sistemi kullanılmıştır. Sulama suyu deneme alanı yakınında bulunan sulama kanalından pompa ile deneme arazisine iletilmiştir. Damla sulama sistemine ait kontrol birimi pompa, gübre tankı $(60 \mathrm{~L})$, filtre, manometre ve küresel vanalardan oluşmaktadır. Damla sulama sistemindeki anaboru, yan boru ve lateral borularının çapları sırasıyla $40 \mathrm{~mm}, 40 \mathrm{~mm}$ ve $16 \mathrm{~mm}$ ve damlatıcıların debisi ise 2 L/h' dir.

Çalışmada Kundu F1 (Capsicum annuum L.) dolmalık biber çeşidi kullanılmıştır. Söz konusu çeşit bölgede üreticiler tarafindan sıklıkla tercih edilen dolmalık biber çeşitlerden birisidir. Kundu F1 yüksek verimli, hastalıklara karşı dirençli, meyve şekli düzgün, yüzeyi pürüzsüz ve dört lopludur. İdeal yetişme koşulları altında meyve boyu 7 $\mathrm{cm}$ ve meyve çapı $6 \mathrm{~cm}$ ' dir. 
Deneme alanının görüntülenmesinde İHA olarak DJI S1000+ oktokopter (DJI, Shenzen, China) kullanılmıştır. Söz konusu İHA' nın ağırlığı 4.4 kg ve optimum hava koşulları altındaki en yüksek havada kalma süresi ise yaklaşık 15 dk' dır. Çalışmada yer kontrol sistemi ile İHA arasındaki bağlantının sağlanmasında DJI 2.4 G Data Link, İHA' nın otonom olarak hareket etmesinde ise DJI A2 uçuş kontrolcüsü kullanılmıştır.

Araştırma alanına ait yüksek çözünürlüklü multispektral görüntülerin elde edilmesinde Micasense Altum (MicaSense, Seattle, USA) model kamera kullanılmıştır. Micasense Altum 5 adet multispektral ve 2 adet termal görüntüleme sensörüne sahiptir. Ayrıca bu sensörlere ek olarak uçuş sırasındaki güneş radyasyon şiddetini ölçen güneşlenme sensörü, GPS sistemi ve bu sensörün kalibre edilmesinde kullanılan kalibrasyon paneli bulunmaktadır. Multispektral sensörlerin çözünürlüğü 3.2 mega pikseldir. Söz konusu kamera ile 120 metre yükseklikten yaklaş1k olarak $5.2 \mathrm{~cm}$ yersel çözünürlüğe sahip multispektral görüntüler elde edilebilmektedir.

Uçuş planın oluşturulması ve uçuşun gerçekleştirilmesinde Universal Ground Control Software (UgCs) 3.2.13 uçuş programlama yazılımından yararlanılmıştır. Micasense Altum kameradan elde edilen ham multispektral görüntülerin spektral yansıma oranı değerine dönüştürülmesinde Python 3.7 kullanılmıştır. Spektral yansıma oranı görüntülerinin ilk olarak yoğun nokta bulutuna daha sonra sırasıyla arazi yükseklik modeli ve mozaik görüntülerinin oluşturulmasında Agisoft MetaShape 1.5.3 yazılımı kullanılmıştır. Mozaik görüntülerin sınıflandırılması ve dolmalık biber bitkilerine ait gölgelerin tespit edilmesinde QGIS 3.2.3 kullanılmıştır.

\subsection{Yöntem}

Dolmalık biber fideleri $70 \mathrm{~cm}$ sıra arası ve $40 \mathrm{~cm}$ sıra üzeri tertip ile 15 Mayıs 2019 tarihinde araştırma sahasına şaşırtılmıştır. Fide dikiminden önce araştırma alanından toprak örnekleri alınmış ve uygulanacak gübre miktarlarının belirlenmesi amaciyla laboratuvarda analiz edilmiştir. $\mathrm{Bu}$ analiz sonucuna göre bitki gelişme dönemi boyunca toplam 6 kg da-1 P2O5 ve 13 kg da-1 N uygulanmıştır. Çalışmada sulama suyu damla sulama yöntemi kullanılarak gerçekleştirilmiştir.

Dolmalık biber yetiştirilen tarım alanı üzerinde uçuş gerçekleştirmeden önce İHA' nın pusula kalibrasyonu yapılmıştır. İHA uçuşu başlamadan hemen önce Micasense Altum kamera ile kalibrasyon plakasının görüntüsü çekilmiştir. Elde edilen bu görüntü güneşlenme sensörünün kalibre edilmesinde kullanılmıştır. İHA uçuşları yerden 30 m yükseklikte ve $2 \mathrm{~m}$ sn-1 hızla gerçekleştirilmiştir. Multispektral kameranın çekim hızı ve iki uçuş güzergahı arasındaki mesafe hesaplanırken en az \%80 bindirme oranı dikkate alınmıştır. İHA uçuşu 3 Temmuz 2019 tarihinde, bulutsuz hava koşulları altında saat 12.30-13.30 arasında gerçekleştirilmiştir.

Micasense Altum multispektral görüntülerin spektral radyans $(\mathrm{W} \cdot \mathrm{sr}-1 \cdot \mathrm{m}-2 \cdot \mathrm{nm}-1)$ değerlerine dönüştürülmesinde üretici firma tarafindan sağlanan radyometrik dönüşüm formülleri uygulanmıştır. (https://support.micasense.com/hc/en-us/articles/115000351194-RedEdge-Camera-Radiometric-Calibration-Model).

$$
L=V(x, y) \times \frac{a_{1}}{g} \times \frac{p-p_{B L}}{t_{\theta}-a_{n} y-a_{g} t_{\theta} y}
$$

Eşitlikte L, spektral radyans; V(x,y), (x,y) görüntü hücresindeki vinyet polinomial fonksiyonu; a1,a2 ve a3, radyometrik kalibrasyon katsayısı; g, sensor kazanım değeri; $p$, normalize edilmiş ham hücre değeri; $p_{B L}$, görüntüdeki siyah seviyesi ve te, görüntü pozlama süresidir. Hesaplama sırasındaki gerekli tüm veriler her bir görüntünün metadata kısmına cihaz tarafından otomatik olarak kaydedilmektedir. Spektral yansıma oranı değerleri ise radyans görüntülerinin güneşlenme sensörüne kaydedilen ve kalibrasyon plakası kullanılarak kalibre edilmiş irradyans değerine oranlanmasıyla elde edilmiştir. Tüm bantlardaki spektral yansıma oranı görüntüleri Agisoft Metahape programı kullanılarak nokta bulutuna dönüştürülmüştür. Söz konusu görüntülerden toplam 23.619.362 adet nokta üretilmiştir. Bu noktalar kullanılarak dijital yükseklik haritası (DEM) oluşturulmuş ve son olarak DEM haritalarından yaklaşık $2 \mathrm{~cm}$ çözünürlüğünde multispektral ortomozaik görüntüler oluşturulmuştur. Ham görüntülerin ortomozaik haline dönüştürülmesi amacıyla Agisoft Metashape 1.5.3 yazılımında kullanılan parametreler Çizelge 1' de verilmiştir. Bu çalışmada bitki gölgelerinin belirlenmesi için üç farklı görüntü sınıflandırma yöntemi (Eğitimli Sınıflandırma (Supervised Classification), Multispektral görüntü ile sınıflandırma ve Sınıf olasılığı (Class Probability)) kullanılmıştır (Şekil 2).

Eğitimli sınıflandırmada, ilk olarak görüntüde bulunan tüm kategorilere (gölge, bitki, toprak, ana boru ve yan borular, lateral borular) ait spektral imzalar belirlenmiştir. Söz konusu spektral imzalar kullanılarak eğitimli sınıflandırma gerçekleştirilmiştir. Multispektral görüntüler ile sınıflandırmada ilk olarak gölge sınıfına ait eşik değerleri deneme-yanılma yöntemi ile tüm bantlar için ayrı olarak belirlenmiştir. Daha sonraki adımda ise bu eşik değeri kullanılarak görüntüde maskeleme yöntemi uygulanmıştır. Böylece sadece bitki gölgelerinin yer aldığı yeni görüntüler elde edilmiştir. Sınıf olasılığı yönteminde ise eğitimli sınıflandırmada olduğu gibi ilk olarak tüm kategorilere ait spektral imzalar tespit edilmiş ve bu spektral imzalara dayalı olarak görüntü sınıflandırılması gerçekleştirilmiştir. 
Çizelge 1. Ortomozaik haritaların oluşturulmasında kullanılan parametreler.

Table 1. Parameters to generating orthomosaic maps.

\begin{tabular}{lrr}
\hline \multirow{2}{*}{ İșlemler } & Parametre & Ayarlar \\
\hline \multirow{3}{*}{ Align Photos } & Accuracy & High \\
\cline { 2 - 3 } & Key Point limit & 40.000 \\
\cline { 2 - 3 } Optimize Camera Alignment & Tie Point limit & 4.000 \\
\hline \multirow{2}{*}{ Build Dense Cloud } & General Parameters & Fit f, cx-cy, k1, k2, k3, b1, b2, p1 and p2 \\
\hline \multirow{3}{*}{ Build DEM } & Quality & Medium \\
\cline { 2 - 3 } & Deepth Filtering & Aggressive \\
\cline { 2 - 3 } Build Orthomosaic & Type & WGS 84/ UTM Zone 36 N (EPSG::32636) \\
\cline { 2 - 3 } & Source Data & Dense Cloud \\
\cline { 2 - 3 } & Interpolation & Extrapolated \\
\hline
\end{tabular}

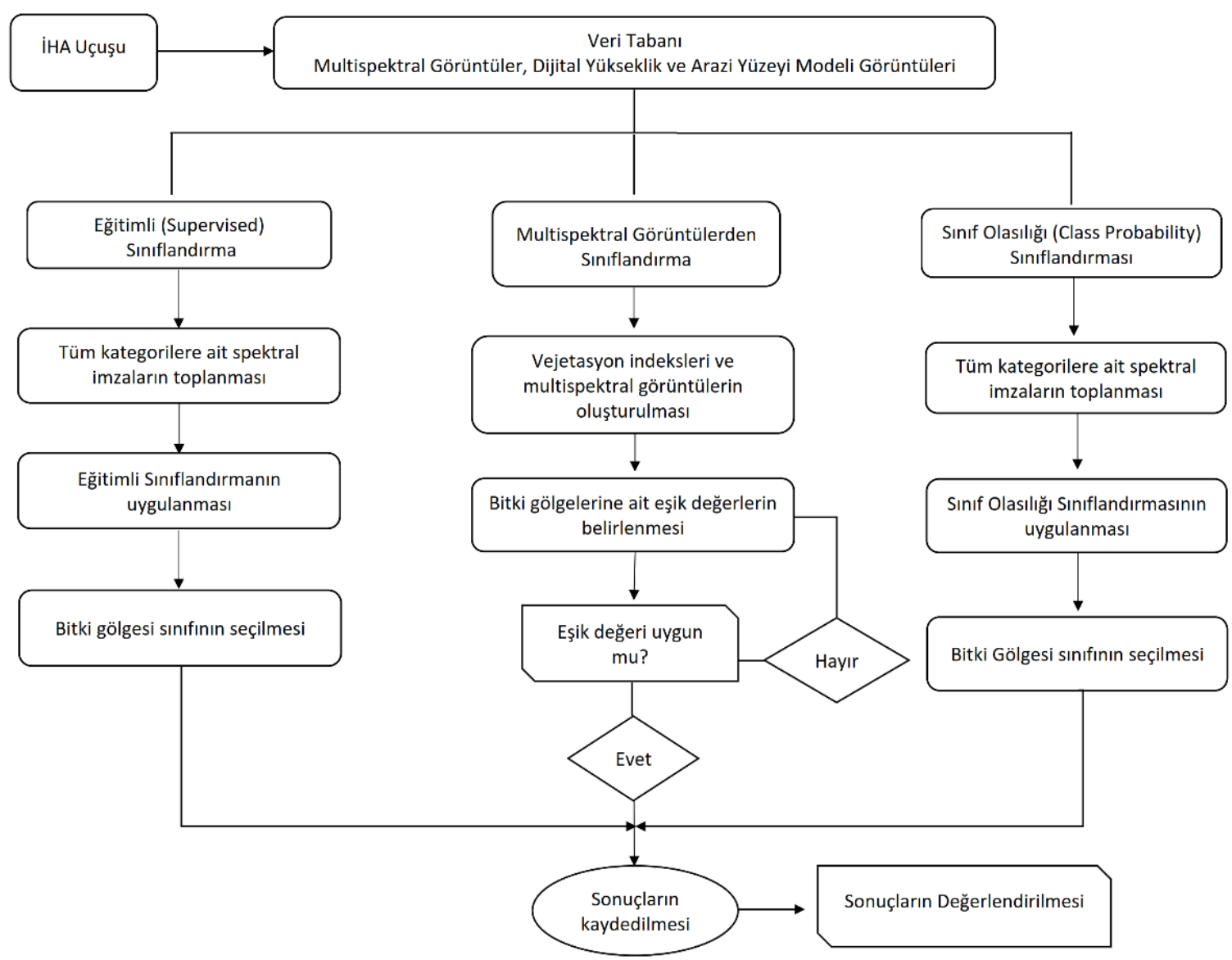

Şekil 2. Çalışmada kullanılan bitki gölge tespit yöntemlerinin akış şeması.

Figure 2. Flow chart of crop shadow detection methods used in the study.

Bitki gölgelerinin tespiti görüntü sınıflandırmaya dayalı olarak gerçekleştirilmiştir. Sınıflandırma yöntemlerinin değerlendirilmesinde ise yaygın olarak hata matrisi kullanılmaktadır (Congalton, 1991). Hata matrisi, gerçek gölge değerleri ile sınıflandırma sonucu tahmin edilen değerin yer aldığı 4 farklı kombinasyonlu bir tablodur. Oluşturulan bu tablodan geri çağırma (Recall), Hassasiyet (Precision), özgünlük (Specificity) ve Doğruluk (Accuracy) hesaplamaları gerçekleştirilmektedir. Bu çalışmada 3 farklı görüntü sınıflandırma yönteminin bitki gölgelerini tespit 
etmedeki hassasiyet dereceleri incelenmiştir. Görüntü sınıflandırma yöntemlerinin hassasiyet dereceleri Eşitlik 2’ ye göre hesaplanmıştır.

$$
\text { Hassasiyet }=\frac{T P}{T P+F P}
$$

Eşitlikte TP, doğru tahmin edilen hücre sayısı, FP ise yanlış tahmin edilen hücre sayısıdır.

Gerçek gölge görüntülerinin oluşturulması amacıyla, görüntüdeki hücreler manuel yöntem ile (1) bitki gölgesi ve (2) gölge olmayan alan olmak üzere iki sınıfa ayrılmıştır. Daha sonra görüntüdeki sınıflar sınıflandırma yöntemleri ile tahmin edilen sonuçlar ile karşılaştırılmıştır.

\section{Bulgular ve Tartışma}

\subsection{Eğitimli sinıflandirma}

Eğitimli sınıflandırma yöntemi ile bitki gölgeleri sınıflandırılmış ve sonuçlar Şekil 3' te verilmiştir. Görüntüler görsel olarak incelendiğinde genel olarak toprak ve dolmalık biber bitkisi başarılı bir biçimde birbirinden ayrılmıştır. Görüntüdeki gölge hücreleri ise yüksek doğruluk seviyesinde tahmin edilmiştir. Genel olarak eğitimli sınıflandırma ile başarılı bir gölge ayrımı yapılmasına rağmen söz konusu yöntemde sınıflandırma öncesinde spektral imzaların belirlenmesi işlemi gerekmektedir. Fakat bu ișlem oldukça zaman alıcı ve işlemin bu konuda eğitimli bir uzman tarfindan yapılması gereklidir. Sona ve ark. (2016)' da İHA görüntülerinde eğitimli sınıflandırma ile bitki ve toprak ayrımı başarılı bir biçimde gerçekleştirilmiştir. Yapılan bir diğer çalışmada ise hiperspektral görüntüler ve LIDAR verileri eğitimli sınıflandırma ile gölgele alanlarının tespit edilmesinde başarılı bir biçimde kullanılmıştır (Tolt ve ark., 2011).
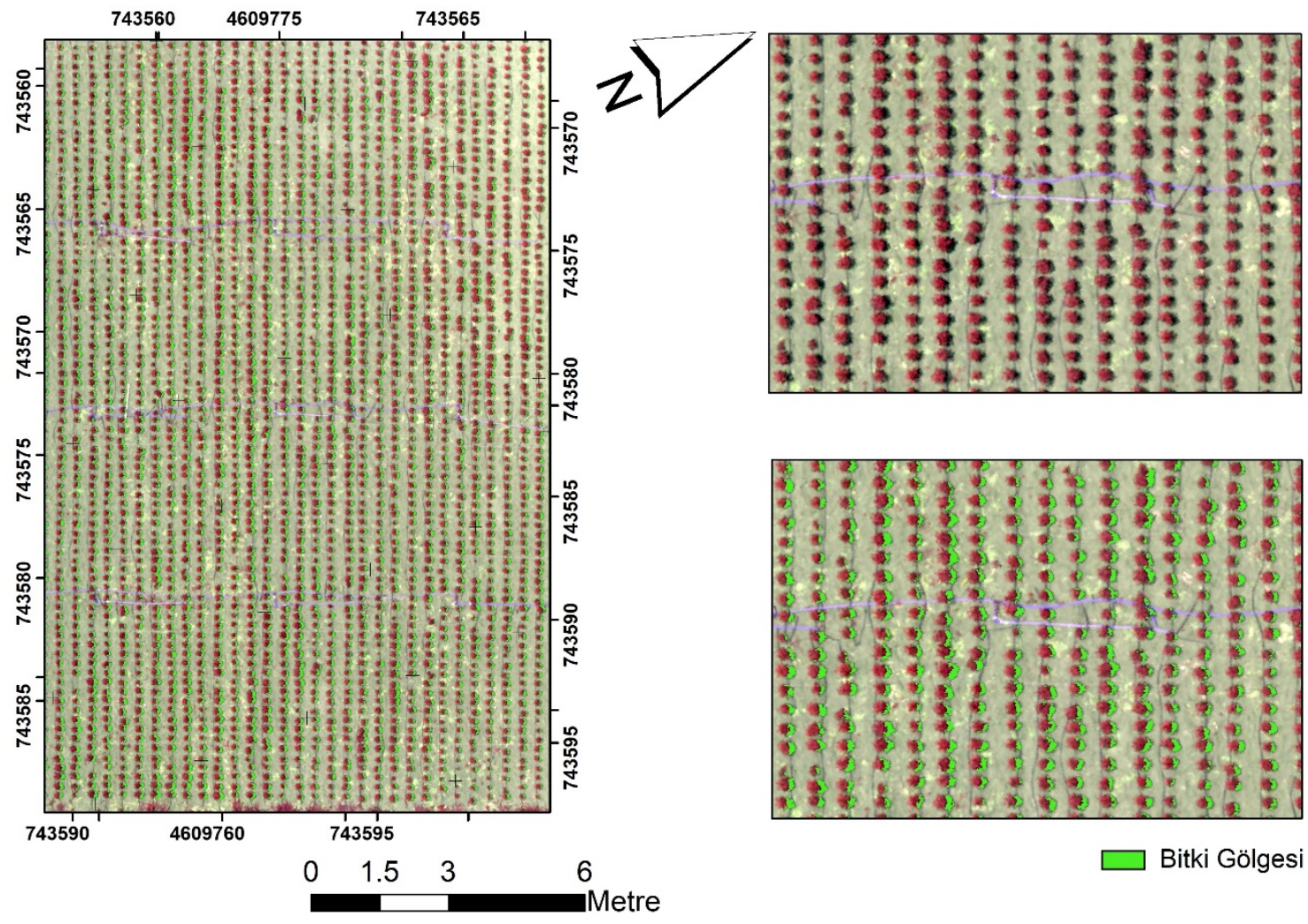

Şekil 3. Çalışma alanının sahte renk (false color) kombinasyonu ve eğitimli sınıflandırma haritası.

Figure 3. Study area false color combination and supervised classification map. 


\subsection{Multispektral görüntü ile sinıflandırma}

Araştırmada multispektral görüntülerden bitki gölge alanlarının belirlenmesi için tüm multispektral görüntü bantları (mavi, yeşil, kırmızı, kırmızı kenar, yakın kızılötesi) ayrı olarak ele alınmıştır. Çalışmada kırmızı kenar (Red Edge) multispektral bant görüntülerinin bitki gölgelerinin tespitinde diğer bant görüntülerinden daha başarılı

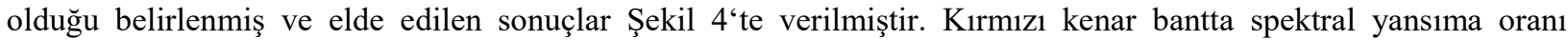
görüntüsünde gölge alanlarını temsil eden hücre değerleri 0.0 ile 0.1 arasında yer almaktadır. Toprak sınıfı 0.10 ile 0.18 arasında değişim göstermektedir. Bitkiler ise genel olarak 0.20 ile 0.27 arasında değişim göstermiştir. Sınıflandırma sonucu incelendiğinde tüm gölge alanlarının net bir biçimde belirlendiği, eğitimli sınıflandırmaya göre gölgelerin geometrik şekilleri daha başarılı bir biçimde ortaya konulmuştur. Xu ve ark. (2019) tarafından yapılan bir araştırmada İHA' dan elde edilen kırmızı kenar görüntülerin bitkilere ait gölgelerin tespitinde başarılı bir biçimde kullanılabileceği bildirilmiştir.

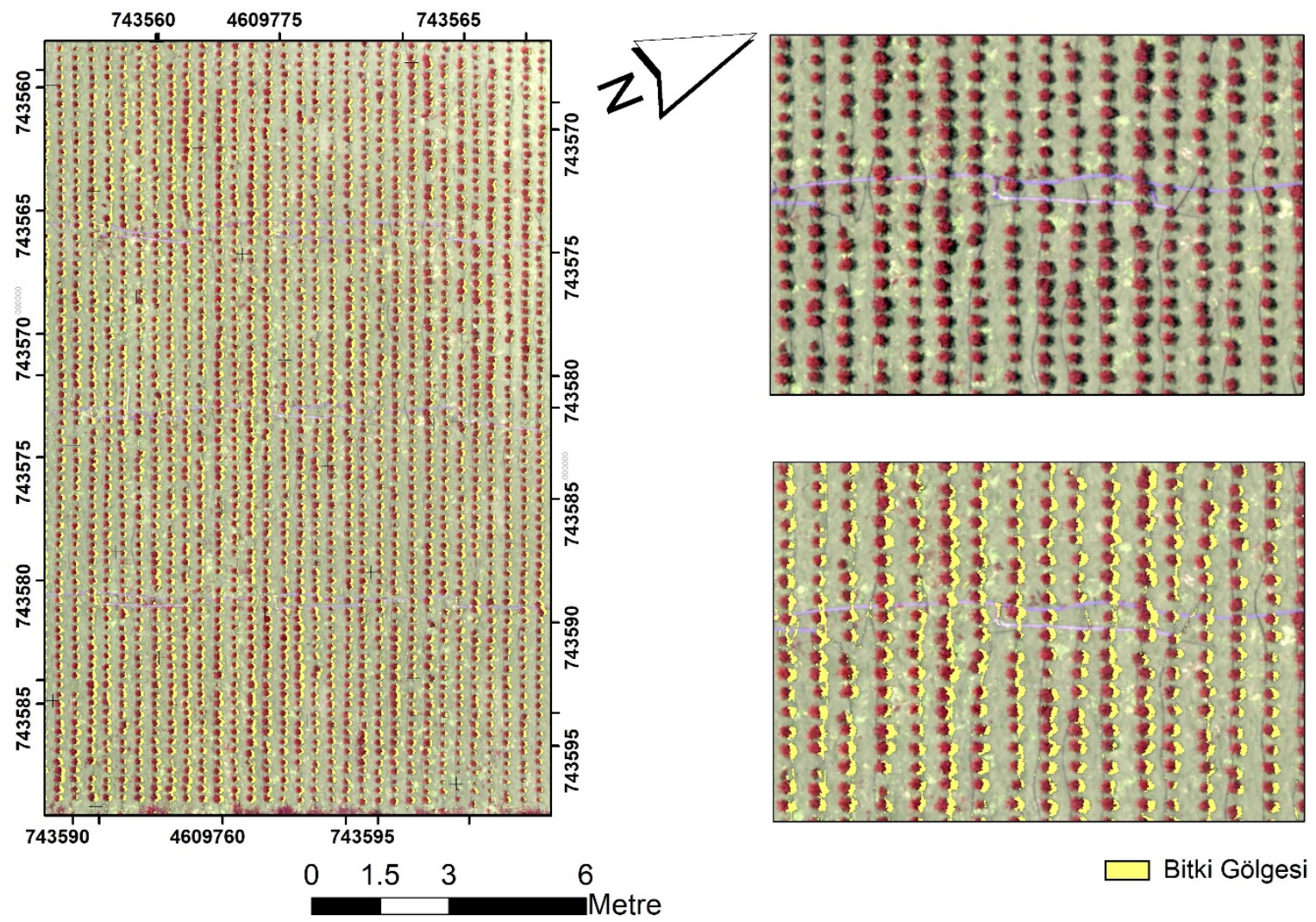

Şekil 4. Çalı̧̧ma alanının sahte renk (false color) kombinasyonu ve kırmızı kenar (Red Edge) multispektral görüntü ile sinıflandırma haritası.

Figure 4. Study area false color combination and supervised classification map.

\subsection{Sinıf olasılı̆̆ yöntemi sinıflandırma}

Yüksek çözünürlüklü İHA görüntülerine sınıf olasıllı̆g yöntemi ile nesne sınıflandırılması gerçekleştirilmiş ve sonuçlar Şekil 5' de verilmiştir. Görüntüler incelendiğinde sınıf olasıllı̆g yönteminin başarısının eğitimli sınıflandırmadan daha yüksek olduğu görülmektedir. Bu sınıflandırmada damla sulama lateral boruları ve bitki gölge alanları eğitimli sınıflandırmadan daha doğru olarak ayrıştırılmasına rağmen, çalışma alanındaki bazı bölgelerde ana ve yan borulara ait görüntü hücreleri de gölge sınıfında yer almıştır. Söz konusu yöntem ile yapılan sınıflandırmanın görsel olarak değerlendirilmesinde kabul edilebilir düzeyde başarı sağlanmasına rağmen, eğitimli sınıflandırma yönteminde olduğu gibi bu yöntemde de sınıflandırma öncesinde spektral imzaların belirlenmesi gerekmektedir. Söz konusu durum büyük ölçekli bir alanda sınıflandırma yapılması durumunda oldukça zaman alıcı ve maliyetli bir işlemdir. 

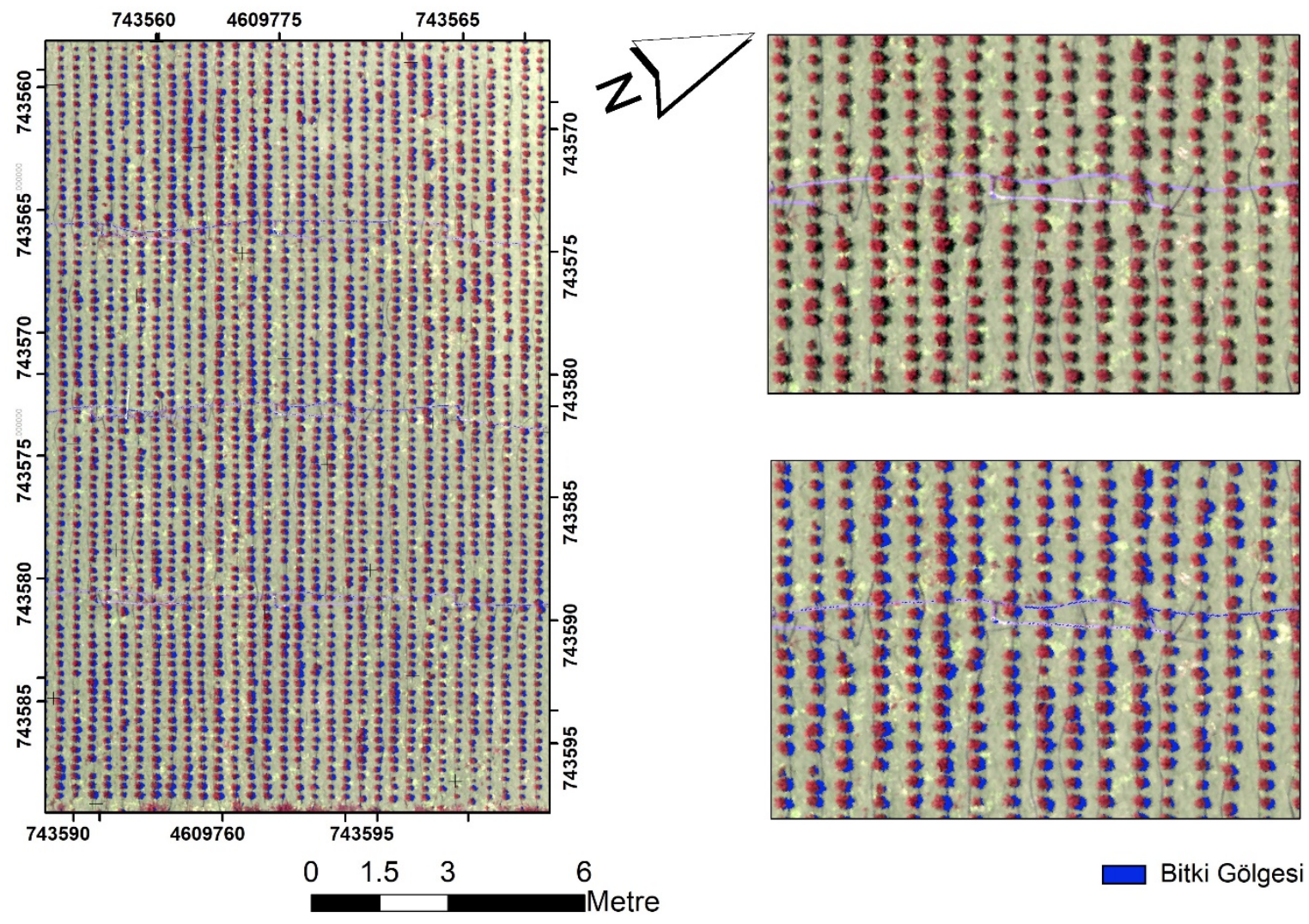

Bitki Gölgesi

Şekil 5. Çalışma alanının sahte renk (false color) kombinasyonu ve sınıf olasılığı yöntemi ile sınıflandırma haritas1.

Figure 5. Study area false color combination class probability map.

\subsection{Görüntü sınıflandırma yöntemlerinin istatistiksel değerlendirilmesi}

Bitki gölgesinin belirlenmesi amacıyla kullanılan sınıflandırma yöntemlerinin hassasiyet dereceleri hesaplanmış ve elde edilen sonuçlar Çizelge 2' de verilmiştir. Buna göre kırmızı kenar spektral yansıma oranı görüntüsü ile yapılan sınıflandırma hassasiyeti (\%94) en yüksek olarak gerçekleşirken, eğitimli sınıflandırma yöntemi ile yapılan sınıflandırmadaki hassasiyet ise en düşük (\%74) olarak hesaplanmıştır. Sınıf olasılığı yöntemi kullanılarak gerçekleştirilen sınıflandırmanın hassasiyet değeri \%82 olarak bulunmuştur. Xu ve ark. (2019)' da bitki gölgelerinin multispektral görüntü ve vejetasyon indeksleri ile belirlenmesi amaçlanmıştır. Çalışmada en yüksek korelasyon kırmızı kenar görüntüleri ile bitki gölgeleri arasında olduğu ve bu ilişkinin belirleme katsayısı (R2) değerinin ise 0.89 olduğu belirtilmiştir.

Çizelge 2. Farklı görüntü sınıflandırma yöntemlerinin bitki gölge tespitindeki hassasiyet sonuçları.

Table 2. Accuracy results of different image classification methods in crop shadow detection.

\begin{tabular}{|c|c|c|c|c|}
\hline & $\begin{array}{c}\text { Doğru } \\
\text { Sınıflandırma } \\
\text { Sayısı } \\
\text { (adet) }\end{array}$ & $\begin{array}{c}\text { Yanlış } \\
\text { Sınıflandırma } \\
\text { Sayısı } \\
\text { (adet) }\end{array}$ & $\begin{array}{c}\text { Toplam } \\
\text { (Adet) }\end{array}$ & $\begin{array}{c}\text { Hassasiyet } \\
\text { (\%) }\end{array}$ \\
\hline Eğitimli Sınıflandırma & 1118 & 381 & 1500 & $\% 74$ \\
\hline $\begin{array}{llr}\text { Multipsektral } & \text { Görüntü } & \text { ile } \\
\text { Sınıflandırma }\end{array}$ & 1410 & 90 & 1500 & $\% 94$ \\
\hline Sınıf Olasılığı Sinıflandırması & 1239 & 261 & 1500 & $\% 82$ \\
\hline
\end{tabular}




\section{Sonuç ve Öneriler}

Nesnelere ait gölgeler yüksek çözünürlük görüntülerde net bir biçimde görülebilen ve spektral yansıma değerinin farklı olması sebebiyle bu görüntülerden yapılan hesaplamalara doğrudan etki eden bir parametredir. Bu çalışmada eğitimli sınıflandırma, multispektral görüntü ile sınıflandırma ve sınıf olasılığı yöntemlerinin dolmalık biber bitkisine ait gölgeleri tespit etmedeki performansları incelenmiştir. Sonuçlar görsel ve istatistiksel olarak incelenmiştir. Elde edilen bu sonuçlara göre kırmızı kenar spektral yansıma oranı ile gerçekleştirilen sınıflandırmada, dolmalık biber bitkisine ait gölgeler eğitimli sınıflandırma ve sınıf olasılı̆̆ı yönteminden daha yüksek hassasiyetle hesaplanmıştır. Bu yöntemi sırasıyla $\% 82$ hassasiyetle sınıf olasılığı yöntemi, \%74 hassasiyetle eğitimli sınıflandırma yöntemi takip etmiştir. Çalışmada kullanılan görüntü sınıflandırma yöntemleri arasında multispektral görüntü ile sınıflandırma hem pratik hem de yüksek doğruluk ile gölge alanlarını tespit edebilmektedir. Ayrıca eğitimli sınıflandırma ve sınıf olasılı̆̆ı yöntemlerinde sınıflandırma öncesinde görüntüdeki nesnelere ait spektral imzaların belirlenmesi bir zorunluluktur. Bu işlem zaman alıcı ve deneyimli bir kullanıcıya ihtiyaç duymaktadır. Bu çalışmadan elde edilen sonuçlara göre yüksek çözünürlüklü İHA ve uydu görüntülerindeki gölge alanları eğitimli sinıflandırma, multispektral görüntü ile sınıflandırma ve sınıf olasılığı yöntemi ile faklı hassasiyet seviyelerinde başarılı bir biçimde filtrelenebilir. Elde edilen bu sonuçlar hassas tarım uygulamalarında sıklıkla kullanılan vejetasyon indekslerinin hatalı olarak hesaplanmasının önüne geçebilir. Ayrıca görüntülerdeki gölgelerin filtrelenmesi ile yüzey enerji dengesi modelleri ile tahmin edilen bitki su tüketimi hesaplamalarındaki hata değeri önemli ölçüde azaltılabilir. Gelecekte farklı İHA sensörleri ve yüksek çözünürlüklü uydu görüntülerinde bitki gölgelerinin tespiti üzerine daha fazla sayıda araştırmaların yapılmasına ihtiyaç duyulmaktadır. Ayrıca üzüm bağları ve meyve ağaçları gibi geniş taç alanına sahip vejetasyonlarda, kanopi üzerine düşen gölgelerin spektral vejetasyon indeksleri ve termal görüntüler ile incelenmesine gereksinim bulunmaktadır.

\section{Teşekkür}

Bu çalışma Ondokuz Mayıs Üniversitesi tarafindan desteklenmiştir (PYO.ZRT.1904.19.001).

\section{Kaynaklar}

Aboutalebi, M., Torres-Rua, A.F., Kustas, W.P., Nieto, H., Coopmans, C., McKee, M., 2019. Assessment of different methods for shadow detection in high-resolution optical imagery and evaluation of shadow impact on calculation of NDVI, and evapotranspiration. Irrigation Sci. 37(3), 407-429.

Berni, J., Zarco-Tejada, P., Suárez, L., González-Dugo, V., Fereres, E., 2009. Remote sensing of vegetation from UAV platforms using lightweight multispectral and thermal imaging sensors. Int. Arch. Photogramm. Remote Sens. Spatial Inform. Sci. 38(6), 6.

Bethsda, M., 1997. Manual of photographic interpretation. 2nd edition. American Society Photogrammetry and remote sensing (ASPRS), American Society Photogrammetry and remote sensing (ASPRS).

Boursianis, A.D., Papadopoulou, M.S., Diamantoulakis, P., Liopa-Tsakalidi, A., Barouchas, P., Salahas, G., Karagiannidis, G., Wan, S., Goudos, S.K., 2020. Internet of Things (IoT) and Agricultural Unmanned Aerial Vehicles (UAVs) in Smart Farming: A Comprehensive Review. Internet of Things. 100187.

Choi, H., Bindschadler, R., 2004. Cloud detection in Landsat imagery of ice sheets using shadow matching technique and automatic normalized difference snow index threshold value decision. Remote Sens Environ. 91(2), 237-242.

Congalton, R.G., 1991. A review of assessing the accuracy of classifications of remotely sensed data. Remote Sens Environ. 37(1), 35-46.

Hsieh, Y.-T., Wu, S.-T., Chen, C.-T., Chen, J.-C., 2016. Analyzing Spectral Characteristics of Shadow Area From High Radiometric Resolution Aerial Images. International Archives of the Photogrammetry, Remote Sensing Spatial Information Sciences. 41.

Huang, J.-B., Chen, C.-S., 2009. A physical approach to moving cast shadow detection, 2009 IEEE International Conference on Acoustics, Speech and Signal Processing. IEEE, pp. 769-772.

Kaivosoja, J., Pesonen, L., Kleemola, J., Pölönen, I., Salo, H., Honkavaara, E., Saari, H., Mäkynen, J., Rajala, A., 2013. A case study of a precision fertilizer application task generation for wheat based on classified hyperspectral data from UAV combined with farm history data, Remote Sensing for Agriculture, Ecosystems, and Hydrology XV. International Society for Optics and Photonics, p. 88870H.

Köksal, E.S., Tasan, M., Artik, C., Gowda, P., 2017. Evaluation of financial efficiency of drip-irrigation of red pepper based on evapotranspiration calculated using an iterative soil water-budget approach. Scientia horticulturae. 226, 398-405. 
Kumar, P., Sengupta, K., Lee, A., 2002. A comparative study of different color spaces for foreground and shadow detection for traffic monitoring system, Proceedings. The IEEE 5th International Conference on Intelligent Transportation Systems. IEEE, pp. 100-105.

Lillesand, T., Kiefer, R., 2000. Remote Sensing and Image Interpretation, 4th edition (New York: Johy Wiley \& Sons). New York, Wiley.

Marques Junior, A., Maria De Castro, D., Guimarães, T.T., Inocencio, L.C., Veronez, M.R., Mauad, F.F., Gonzaga Jr, L., 2020. Statistical assessment of cartographic product from photogrammetry and fixed-wing UAV acquisition. European Journal of Remote Sensing. 53(1), 27-39.

MGM, 2020. https://www.mgm.gov.tr/iklim/iklim-siniflandirmalari.aspx=BAFRA. (Erişim tarihi: 15/05/2020).

Nieto, H., Kustas, W.P., Torres-Rúa, A., Alfieri, J.G., Gao, F., Anderson, M.C., White, W.A., Song, L., del Mar Alsina, M., Prueger, J.H., 2019. Evaluation of TSEB turbulent fluxes using different methods for the retrieval of soil and canopy component temperatures from UAV thermal and multispectral imagery. Irrigation Sci. 37(3), 389-406.

Novák, V., Křížová, K., Napitupulu, R., 2018. Influence of North Sumatra Maize (Zea mays L.) monoculture on soil properties using free Sentinel 2 imagery. 2nd Nommensen International Conference on Technology and Engineering 19-20 July 2018. Medan, Indonesia, p. 012076.

Ortega-Farías, S., Ortega-Salazar, S., Poblete, T., Kilic, A., Allen, R., Poblete-Echeverría, C., Ahumada-Orellana, L., Zuñiga, M., Sepúlveda, D., 2016. Estimation of energy balance components over a drip-irrigated olive orchard using thermal and multispectral cameras placed on a helicopter-based unmanned aerial vehicle (UAV). Remote Sens-Basel. 8(8), 638.

Peña, J.M., Torres-Sánchez, J., Serrano-Pérez, A., De Castro, A.I., López-Granados, F., 2015. Quantifying efficacy and limits of unmanned aerial vehicle (UAV) technology for weed seedling detection as affected by sensor resolution. Sensors. 15(3), 5609-5626.

Poblete, T., Ortega-Farías, S., Ryu, D., 2018. Automatic coregistration algorithm to remove canopy shaded pixels in UAV-borne thermal images to improve the estimation of crop water stress index of a drip-irrigated Cabernet Sauvignon vineyard. Sensors. 18(2), 397.

Qiao, X., Yuan, D., Li, H., 2017. Urban shadow detection and classification using hyperspectral image. Journal of the Indian Society of Remote Sensing. 45(6), 945-952.

Review, M.T., 2020. 10 Breakthrough Technologies 2014. https://www.technologyreview.com/10-breakthroughtechnologies/2014/. (Erişim tarihi: 5 Mayıs, 2020).

Rosin, P.L., Ellis, T.J., 1995. Image difference threshold strategies and shadow detection, BMVC. Citeseer, pp. 347356.

Sandnes, F.E., 2011. Determining the geographical location of image scenes based on object shadow lengths. Journal of Signal Processing Systems. 65(1), 35-47.

Shin, J.-i., Seo, W.-w., Kim, T., Park, J., Woo, C.-S., 2019. Using UAV multispectral images for classification of forest burn severity — A case study of the 2019 Gangneung forest fire. Forests. 10(11), 1025.

Shiting, W., Hong, Z., 2013. Clustering-based shadow edge detection in a single color image, Proceedings 2013 International Conference on Mechatronic Sciences, Electric Engineering and Computer (MEC). IEEE, pp. 10381041.

Siala, K., Chakchouk, M., Chaieb, F., Besbes, O., 2004. Moving shadow detection with support vector domain description in the color ratios space, Proceedings of the 17th International Conference on Pattern Recognition, 2004. ICPR 2004. IEEE, pp. 384-387.

Sirmacek, B., Unsalan, C., 2008. Building detection from aerial images using invariant color features and shadow information, 2008 23rd International Symposium on Computer and Information Sciences. IEEE, pp. 1-5.

Sona, G., Passoni, D., Pinto, L., Pagliari, D., Masseroni, D., Ortuani, B., Facchi, A., 2016. UAV multispectral survey to map soil and crop for precision farming applications, Remote Sensing and Spatial Information Sciences Congress: International Archives of the Photogrammetry Remote Sensing and Spatial Information Sciences Congress: 19 July. International Society for Photogrammetry and Remote Sensing (ISPRS), pp. 10231029.

Tolt, G., Shimoni, M., Ahlberg, J., 2011. A shadow detection method for remote sensing images using VHR hyperspectral and LIDAR data, 2011 IEEE international geoscience and remote sensing symposium. IEEE, pp. 4423-4426.

Tunca, E., Köksal, E.S., Çetin, S., Ekiz, N.M., Balde, H., 2018. Yield and leaf area index estimations for sunflower plants using unmanned aerial vehicle images. Environmental Monitoring and Assessment. 190(11). https://doi.org/10.1007/s10661-018-7064-x.

Werner, T., Bebbington, A., Gregory, G., 2019. Assessing impacts of mining: Recent contributions from GIS and remote sensing. The Extractive Industries Society. 6(3), 993-1012. 
Xia, H., Chen, X., Guo, P., 2009. A shadow detection method for remote sensing images using affinity propagation algorithm, 2009 IEEE International Conference on Systems, Man and Cybernetics. IEEE, pp. 3116-3121.

Xu, N., Tian, J., Tian, Q., Xu, K., Tang, S., 2019. Analysis of Vegetation Red Edge with Different Illuminated/Shaded Canopy Proportions and to Construct Normalized Difference Canopy Shadow Index. Remote Sens-Basel. 11(10), 1192.

Zheng, H., Cheng, T., Li, D., Yao, X., Tian, Y., Cao, W., Zhu, Y., 2018. Combining unmanned aerial vehicle (UAV)-based multispectral imagery and ground-based hyperspectral data for plant nitrogen concentration estimation in rice. Frontiers in plant science. 9, 936.

Zhu, Z., Woodcock, C.E., 2012. Object-based cloud and cloud shadow detection in Landsat imagery. Remote Sens Environ. 118, 83-94. 